\title{
Postoperative delirium in elderly patients with critical limb ischemia undergoing major leg amputation: a retrospective study
}

\author{
Young-Hee Shin ${ }^{1}$, Jin Sun Yoon ${ }^{2}$, Hee Jung Jeon ${ }^{2}$, Youngbae B Kim³ \\ Young Soo Kim², and Ju Young Park ${ }^{2}$ \\ ${ }^{I}$ Department of Anesthesiology and Pain Medicine, Samsung Medical Center, Sungkyunkwan University School \\ of Medicine, Departments of ${ }^{2}$ Anesthesiology and Pain Medicine, ${ }^{3}$ Orthopedic Surgery, Veterans Health Service \\ Medical Center, Seoul, Korea
}

Background: Critical limb ischemia has been identified as a risk factor for the incidence of postoperative delirium in elderly patients. Limb amputation is the last option in critical limb ischemia treatments. We investigated the incidence and predisposing factors of postoperative delirium in patients undergoing major leg amputation.

Methods: From January 2012 to December 2016, 121 patients aged over 60 years who had undergone major leg amputation were enrolled in this study. Various factors related to the patients' outcomes were assessed, including demographic, preoperative laboratory, anesthetic, surgical, and postoperative indicators.

Results: Twenty two patients were excluded and 99 patients were assigned to either the delirium group or no delirium group. Forty of them (40\%) developed a delirium during 30 days postoperatively. Univariate analysis implied that endstage renal disease on hemodialysis, alcohol consumption, C-reactive protein, staying in an intensive care unit (ICU), duration of an ICU stay, occurrence of complications, and mortality during six months, were the factors that accounted for significant differences between the two groups. In multivariate analysis, three factors were significantly related to the development of delirium: mortality during six months (odds ratio $[\mathrm{OR}]=13.86,95 \% \mathrm{CI}[2.10-31.90])$, alcohol $(\mathrm{OR}=8.18$, 95\% CI [1.13-16.60]), and hemodialysis ( $\mathrm{OR}=4.34,95 \%$ CI [2.06-93.08]).

Conclusions: Approximately $40 \%$ of the elderly patients suffered from postoperative delirium in major leg amputation. Identifying those with risk factors for postoperative delirium and intervening at the early stage will be of great benefit in major leg amputations for the elderly population.

Keywords: Amputation; Delirium; Elderly patients; Ischemia; Leg.

Corresponding author: Jin Sun Yoon, M.D.

Department of Anesthesiology and Pain Medicine, Veterans Health Service Medical Center, 53, Jinhwangdo-ro 61-gil, Gangdong-gu, Seoul 05368, Korea

Tel: 82-2-2225-1415, Fax: 82-2-2225-1946

Email: medisun74@naver.com

ORCID: https://orcid.org/0000-0002-7133-1814

Received: April 28, 2017.

Revised: May 31, 2017 (1st); June 19, 2017 (2nd).

Accepted: July 18, 2017.

Korean J Anesthesiol 2018 August 71(4): 311-316

https://doi.org/10.4097/kja.d.18.27108

\section{Introduction}

Postoperative delirium is defined as an acute change in cognitive status characterized by fluctuating consciousness and inattention, occurring within 30 days after a surgery [1]. The incidence of postoperative delirium varies from $2 \%$ to $72 \%$, with higher rates among elderly patients [2]. The significance of etiological parameters differs, depending on the studies; however, old age has been proven to be a common predisposing factor [3]. A reduced cognitive reserve of elderly patients is a greater risk

(c) This is an open-access article distributed under the terms of the Creative Commons Attribution Non-Commercial License (http://creativecommons.org/ licenses/by-nc/4.0/), which permits unrestricted non-commercial use, distribution, and reproduction in any medium, provided the original work is properly cited. 
for delirium or cognitive decline in the postoperative period [4]. As the population of the elderly has been growing over decades, the occurrence of postoperative delirium will also continue to increase.

Postoperative delirium results in a prolonged recovery time, difficulty in postoperative care, longer intensive care unit and hospital stays, as well as higher mortality and morbidity rates [5]. The assessment of risk factors is important for preventing and managing delirium in patients. However, fluctuating symptoms may lead to delays of the diagnosis and treatment. In the hypoactive delirium subtype, which is more common in the elderly, the patient outwardly seems calm or somnolent, so it is frequently missed, although related with a poor prognosis $[1,6]$.

Critical limb ischemia is the most advanced form among the peripheral artery diseases and has been identified as a risk factor for postoperative delirium in elderly patients [3]. Limb amputation is the last option when revascularization is no longer possible in critical limb ischemia treatments [7]. The identified risk factors of postoperative delirium in lower limb ischemia are age, end-stage renal failure, multiple occlusive lesions, cognitive impairment, and critical limb ischemia [2]. However, no study has specifically analyzed the occurrence and risk factors of postoperative delirium in patients with critical limb ischemia with a focus on only major leg amputation surgery. A few investigations exist that included amputated populations and were associated with postoperative delirium in critical limb ischemia, but they either contained various types of amputation surgery or enrolled only a small number of patients with a major amputation [8-10]. We aimed to investigate the incidence and perioperative predisposing factors of postoperative delirium in elderly patients undergoing a major leg amputation.

\section{Materials and Methods}

Ethical approval for this retrospective study was obtained from the Institutional Review Board of our hospital. Patients who were 60 years or older undergoing major leg amputation from January 2012 to December 2016 were recruited and followed up for six months. They were either assigned to a delirium group or a no delirium group. Postoperative delirium was assessed using the Confusion Assessment Scale (CAM), which is sensitive, specific, reliable and easy to use for the identification of delirium [11]. The presence of delirium was evaluated once a day, for 30 days postoperatively.

Demographic data including gender, age, height, weight, body mass index, and the physical status according to the American Society of Anesthesiologists were collected through chart reviews. The physical performance status was scored with the Eastern Cooperative Oncology Group (ECOG) scale; 0: Fully active, able to carry on all pre-disease performance without re- striction, 1: Restricted in physically strenuous activity but ambulatory and able to carry out work of a light or sedentary nature, 2: Ambulatory and capable of all selfcare but unable to carry out any work activities. Up and about more than $50 \%$ of waking hours, 3: Capable of only limited selfcare, confined to bed or chair more than $50 \%$ of waking hours, 4 : Completely disabled. Cannot carry on any selfcare. Totally confined to bed or chair, 5: Dead [12]. Comorbidities were divided into the following categories: hypertension, diabetes mellitus, end-stage renal disease on hemodialysis, cardiac (angina pectoris, myocardial infarction, rhythm disorder, valve disorder, cardiomyopathy, and heart failure), neurologic (cerebrovascular accident, transient ischemic attack, and Parkinson's disease), renal (acute renal failure, chronic renal failure, glomerulopathy, and glomerulonephritis), pulmonary (chronic obstructive disease and asthma), and hepatic (liver cirrhosis) diseases. Other predisposing factors such as alcohol, smoking, visual and hearing aids were also evaluated. Alcohol consumption was marked if more than one drink of distilled alcohol or a bottle of beer was consumed two or more times a week.

Preoperative laboratory variables were hemoglobin, sodium, potassium, blood urea nitrogen (BUN), creatinine, albumin, total protein, the erythrocyte sedimentation rate (ESR), C-reactive protein (CRP), fasting blood sugar (FBS), $\mathrm{PaO}_{2}$, and $\mathrm{PaCO}_{2}$.

Anesthetic and surgical data were extracted from the anesthesia records. Types of anesthesia (general or regional anesthesia), anesthesia duration, types of operation (above or below knee amputation), duration of the operation, estimated blood loss (EBL), transfusion of blood products, and use of inotropics were included in the operative data.

Postoperatively, patients were evaluated by intensive care unit (ICU) stays, duration of ICU stays, occurrence of complications, as well as hospital stays and mortality during six months.

All statistical analyses were performed using the SPSS statistics software (version 20.0, IBM Corp., USA). Differences in categorical values were assessed using the chi-square test. If more than $20 \%$ of the expected frequencies were less than 5, Fisher's exact test was conducted. The Kolmogorov-Smirnov test was used to test for normality in continuous variables. Group differences were tested using the Mann-Whitney $U$ test or student $t$ tests as applicable. $\mathrm{P}$ values less than 0.05 were considered significant. Variables with statistical significance in univariate analyses were assessed by multivariate logistic regression analysis to determine the degree of the variables' association with the odds ratio (OR) and $95 \% \mathrm{CI}$.

\section{Results}

Out of the 121 patients, 99 patients were included in the study. Twenty two were excluded because of pre-existing de- 
mentia and mental changes, communication difficulty, and a concomitant additional surgery. Forty of the 99 subjects (40\%) undergoing major leg amputation postoperatively developed a delirium during 30 days. Physical characteristics (gender, age, height, weight, and body mass index), American Society of Anesthesiologists status, and ECOG performance status were similar in both the delirium and no delirium groups (Table 1). In a comparison of comorbidities, only end-stage renal disease on hemodialysis was significantly higher in the delirium group (28\%) than in the no delirium group $(10 \%)(\mathrm{P}=0.025)$. The number of patients who ingested more than one drink of distilled alcohol or a bottle of beer two or more times a week was significantly different between the groups (30\% vs. $9 \%, \mathrm{P}=$ 0.005).

With regard to the preoperative laboratory variables, the CRP level in the delirium group of $143.1 \pm 84.6 \mathrm{mg} / \mathrm{L}$ was significantly higher than in the no-delirium group with $93.9 \pm 81.4 \mathrm{mg} / \mathrm{L}(\mathrm{P}$

Table 1. Demographic Data

\begin{tabular}{lccc}
\hline & $\begin{array}{c}\text { Delirium } \\
(\mathrm{n}=40)\end{array}$ & $\begin{array}{c}\text { No delirium } \\
(\mathrm{n}=59)\end{array}$ & P value \\
\hline Gender $(\mathrm{F} / \mathrm{M})$ & $3 / 37(8 \%)$ & $2 / 57(4 \%)$ & 0.391 \\
Age $(\mathrm{yr})$ & $73.6 \pm 7.0$ & $73.3 \pm 8.0$ & 0.829 \\
Height $(\mathrm{cm})$ & $165.4 \pm 7.4$ & $166.6 \pm 6.9$ & 0.445 \\
Weight $(\mathrm{kg})$ & $56.4 \pm 11.2$ & $57.1 \pm 10.7$ & 0.750 \\
BMI $\left(\mathrm{kg} / \mathrm{m}^{2}\right)$ & $20.7 \pm 3.4$ & $20.6 \pm 3.0$ & 0.825 \\
ASA status (I/II/III/IV) & $0 / 17 / 23 / 0$ & $1 / 30 / 26 / 2$ & 0.404 \\
ECOG performance status & $3 / 19 / 17 / 1$ & $4 / 29 / 22 / 4$ & 0.875 \\
(1/2/3/4) & & & \\
Comorbidity & & & \\
Hypertension & $33(83 \%)$ & $39(66 \%)$ & 0.072 \\
Diabetes mellitus & $31(78 \%)$ & $42(71 \%)$ & 0.484 \\
Hemodialysis & $11(28 \%)$ & $6(10 \%)$ & 0.025 \\
Cardiac disease & $25(63 \%)$ & $28(48 \%)$ & 0.141 \\
Neurologic disease & $14(35 \%)$ & $30(51 \%)$ & 0.119 \\
Renal disease & $18(45 \%)$ & $20(34 \%)$ & 0.265 \\
Pulmonary disease & 0 & $5(9 \%)$ & 0.079 \\
Hepatic disease & $1(3 \%)$ & 0 & 0.353 \\
Other predisposing factors & & & \\
Alcohol & $12(30 \%)$ & $5(9 \%)$ & 0.005 \\
Smoking & $8(20 \%)$ & $10(17 \%)$ & 0.699 \\
Visual aids & $6(15 \%)$ & $12(20 \%)$ & 0.499 \\
Hearing aids & 0 & $1(2 \%)$ & 1.000 \\
\hline
\end{tabular}

Values are expressed as the mean \pm SD or number (\%). BMI: body mass index, ASA: American Society of Anesthesiologists, ECOG: Eastern Cooperative Oncology Group. ECOG performance status (0: Fully active, able to carry on all pre-disease performance without restriction, 1: Restricted in physically strenuous activity but ambulatory and able to carry out work of a light or sedentary nature, 2: Ambulatory and capable of all selfcare but unable to carry out any work activities. Up and about more than $50 \%$ of waking hours, 3: Capable of only limited selfcare, confined to bed or chair more than $50 \%$ of waking hours, 4 : Completely disabled. Cannot carry on any selfcare. Totally confined to bed or chair, 5: Dead).
$=0.005)$ (Table 2$)$.

There were no significant differences related to types of anesthesia (general or regional anesthesia), anesthesia duration, types of operation (above or below knee amputation), duration of the operation, EBL, transfusion of blood products, and use of inotropics during the procedure (Table 3 ).

Postoperatively, the number of patients who were treated in an ICU was higher in the delirium group $(24 / 40,60 \%)$ than in the no delirium group $(15 / 59,25 \%)(P=0.001)$ and the mean durations of ICU stays also differed between the two groups $(17.2 \pm 15.6$ days vs. $7.8 \pm 12.1$ days, $\mathrm{P}=0.040$, respectively $)$ (Table 4$)$. The rate of complications was higher in the delirium group $(11 / 40,28 \%)$ than in the no delirium group $(5 / 59,8 \%)(\mathrm{P}$ $=0.024)$. The types of postoperative complication were sepsis,

Table 2. Preoperative Laboratory Data

\begin{tabular}{lccc}
\hline & $\begin{array}{c}\text { Delirium } \\
(\mathrm{n}=40)\end{array}$ & $\begin{array}{c}\text { No delirium } \\
(\mathrm{n}=59)\end{array}$ & P value \\
\hline Hemoglobin $(\mathrm{g} / \mathrm{dl})$ & $10.3 \pm 1.5$ & $10.6 \pm 1.5$ & 0.420 \\
Sodium $(\mathrm{mEq} / \mathrm{L})$ & $135.7 \pm 3.6$ & $136.0 \pm 4.1$ & 0.662 \\
Potassium $(\mathrm{mEq} / \mathrm{L})$ & $4.1 \pm 0.6$ & $4.1 \pm 0.6$ & 0.849 \\
$\mathrm{BUN}(\mathrm{mg} / \mathrm{dl})$ & $31.3 \pm 18.2$ & $25.0 \pm 15.4$ & 0.064 \\
Creatinine $(\mathrm{mg} / \mathrm{dl})$ & $2.6 \pm 2.7$ & $2.2 \pm 2.6$ & 0.468 \\
Albumin $(\mathrm{g} / \mathrm{dl})$ & $3.1 \pm 0.5$ & $3.3 \pm 0.7$ & 0.093 \\
Total $\mathrm{protein}(\mathrm{g} / \mathrm{dl})$ & $6.2 \pm 0.8$ & $6.3 \pm 0.8$ & 0.429 \\
ESR $(\mathrm{mm} / \mathrm{h})$ & $84.7 \pm 33.6$ & $75.7 \pm 32.4$ & 0.188 \\
$\mathrm{CRP}(\mathrm{mg} / \mathrm{L})$ & $143.1 \pm 84.6$ & $93.9 \pm 81.4$ & 0.005 \\
$\mathrm{FBS}(\mathrm{mg} / \mathrm{dl})$ & $144.8 \pm 52.5$ & $140.0 \pm 69.1$ & 0.711 \\
$\mathrm{PaO}_{2}(\mathrm{mmHg})$ & $81.7 \pm 20.1$ & $85.0 \pm 14.3$ & 0.349 \\
$\mathrm{PaCO}_{2}(\mathrm{mmHg})$ & $34.7 \pm 7.3$ & $33.8 \pm 6.3$ & 0.530 \\
\hline
\end{tabular}

Values are expressed as the mean \pm SD. BUN: blood urea nitrogen, ESR: erythrocyte sedimentation rate, CRP: C-reactive protein, FBS: fasting blood sugar.

Table 3. Anesthetic and Surgical Data

\begin{tabular}{lccc}
\hline & $\begin{array}{c}\text { Delirium } \\
(\mathrm{n}=40)\end{array}$ & $\begin{array}{c}\text { No Delirium } \\
(\mathrm{n}=59)\end{array}$ & P value \\
\hline Type of anesthesia & & & 0.329 \\
$\quad$ General anesthesia & $16(40 \%)$ & $18(31 \%)$ & \\
$\quad$ Regional anesthesia & $24(60 \%)$ & $41(70 \%)$ & \\
Duration of anesthesia (min) & $150.5 \pm 35.6$ & $152.5 \pm 51.0$ & 0.818 \\
Type of operation & & & 0.164 \\
$\quad$ AK amputation & $5(13 \%)$ & $14(24 \%)$ & \\
$\quad$ BK amputation & $35(88 \%)$ & $45(76 \%)$ & \\
Duration of operation (min) & $110.4 \pm 34.3$ & $117.5 \pm 46.6$ & 0.408 \\
EBL (ml) & $190.8 \pm 136.7$ & $211.9 \pm 150.4$ & 0.479 \\
Transfusion & $11(28 \%)$ & $12(20 \%)$ & 0.408 \\
Use of inotropic during & $13(33 \%)$ & $22(37 \%)$ & 0.625 \\
$\quad$ operation & & & \\
\hline
\end{tabular}

Values are expressed as the mean $\pm \mathrm{SD}$ or number (\%). AK: above knee, BK: below knee, EBL: estimated blood loss. 
Table 4. Postoperative Data

\begin{tabular}{lccr}
\hline & $\begin{array}{c}\text { Delirium } \\
(\mathrm{n}=40)\end{array}$ & $\begin{array}{c}\text { No delirium } \\
(\mathrm{n}=59)\end{array}$ & P value \\
\hline ICU care & $24(60 \%)$ & $15(25 \%)$ & 0.001 \\
Duration of ICU stay (day) & $17.2 \pm 15.6$ & $7.8 \pm 12.1$ & 0.040 \\
Occurrence of complication & $11(28 \%)$ & $5(9 \%)$ & 0.024 \\
Hospital stay (day) & $94.8 \pm 132.1$ & $98.4 \pm 87.1$ & 0.872 \\
Mortality during six months & $14(35 \%)$ & $3(5 \%)$ & $<0.001$ \\
\hline
\end{tabular}

Values are expressed as the mean \pm SD or number (\%). ICU: intensive care unit.

septic shock, pneumonia, wound problems, heart failure, acute renal failure, and multi-organ failure. The mortality during six months was also significantly higher in the delirium group $(14 / 40,35 \%)$ than in the no delirium group $(3 / 59,5 \%)(\mathrm{P}<$ $0.001)$.

The univariate analysis indicated that end-stage renal disease on hemodialysis, alcohol consumption, CRP, ICU stays, duration of ICU stays, occurrence of complications, and mortality during six months were the factors that accounted for the differences between the two groups and they were further evaluated in a multivariate logistic regression analysis (Table 5). Three factors were significantly related to the development of delirium: mortality during six months ( $\mathrm{OR}=13.86,95 \% \mathrm{CI}$ [2.10-31.90]), alcohol $(\mathrm{OR}=8.18,95 \% \mathrm{CI}[1.13-16.60])$, and end-stage renal disease on hemodialysis ( $\mathrm{OR}=4.34,95 \% \mathrm{CI}$ [2.06-93.08]).

\section{Discussion}

In this retrospective study, the incidence of delirium following major leg amputation was $40 \%$ postoperatively. Endstage renal disease on hemodialysis, alcohol consumption, the preoperative CRP level, the number of patients treated in an ICU, durations of ICU care, as well as rates of complication and mortality during six months were significantly different between the two groups. Among those variables, mortality during six months, alcohol, and hemodialysis were significantly related to the development of delirium in multivariate logistic regression. Alcohol and hemodialysis could be regarded as independent predicting factors of delirium. For the mortality during six months, its preceding relationship to delirium is unclear, so we could not affirm it to be a predicting factor.

The incidence of postoperative delirium varies depending on the types of procedure. In patients who underwent vascular surgery such as aortic, carotid, endovascular, bypass, endarterectomy, arteriovenous shunt, percutaneous intervention, and amputation, the occurrence ranged from $5 \%$ to $43 \%[5,8-10,13]$. Two published incidence rates of delirium after any kind of leg amputation were $17 \%$ [9] and 20\% [10]. One study reported that
Table 5. Logistic Regression Analysis Results on Delirium

\begin{tabular}{lrlc}
\hline & OR & \multicolumn{1}{c}{$95 \%$ CI } & P value \\
\hline Mortality during six months & 13.86 & $2.10-31.90$ & 0.002 \\
Alcohol & 8.18 & $1.13-16.60$ & 0.032 \\
Hemodialysis & 4.34 & $2.06-93.08$ & 0.007 \\
ICU care & 1.71 & $0.52-5.60$ & 0.377 \\
Occurrence of complication & 0.80 & $0.11-5.79$ & 0.821 \\
CRP & & & \\
$\quad$ 10-100 & 4.39 & $0.30-64.74$ & 0.282 \\
$\quad>100$ & 10.97 & $0.76-157.48$ & 0.078 \\
$\quad$ Duration of ICU stay (day) & & & \\
$\quad>10$ & 2.09 & $0.35-12.56$ & 0.419 \\
\hline
\end{tabular}

Values are expressed as ORs and their 95\% CIs. OR: odds ratio, ICU: intensive care unit, CRP: C-reactive protein.

the incidence rate associated with major leg amputation (below and above knee amputations) was 61\% (11/18) [8].

Amputation surgery was established as a predictor of postoperative delirium occurrence in vascular surgical procedures $[9,10]$. Critical limb ischemia is frequently related to systemic atherosclerosis and its negative impacts on patients' outcomes [14]. In addition, systemic atherosclerosis contributes to cognitive decline in elderly patients and cognitive impairment is a well-known risk factor for delirium $[15,16]$. However, to our knowledge, no study has specifically investigated the incidence and risk factors of delirium after surgery with a sole focus on only lower limb amputation which this investigation of major leg amputation (below and above knee amputations) did. Limb ischemia is often accompanied by limitations of physical performance, which is a significant risk factor for delirium [17]. The ECOG scale for performance status was applied to all patients at admission to evaluate their daily living abilities [12]. Most patients $(88 \%, 87 / 99)$ were on grade 2 or 3 , which indicated they were unable to carry out any work activities or that they were only capable of limited selfcare. Five percent (5/99) of the patients were even completely disabled and could not carry on any selfcare. However, our results revealed no significant correlation between daily functioning and delirium.

The rate of delirium in our study was $40 \%$ (40/99), which is slightly lower compared with research by van Eijsden et al. [8] where 11 out of 18 patients (61\%) undergone major amputation surgery. However, in that study, the number of subjects with amputation procedures was small and all included critical limb ischemia patients were relatively old, with a median age of 78 years (interquartile range of 71-82 years). Our patients' median age was 71 years (interquartile range $69-78$ years) and the mean age was similar in both the delirium and no delirium group (73.6 \pm 7.0 vs. $73.3 \pm 8.0$, respectively). Although we could not establish a relationship between delirium and age, advanced age has been identified as a strong risk factor for postoperative delirium 
$[3,5,9]$. Age represents a potent risk factor for delirium, probably due to the accumulation of medical and other comorbidities with declined reserves throughout later life [18].

A recent study on lower limb ischemia reported that endstage renal disease is an important risk factor of delirium, suggesting that delirium with an increased BUN level may result from the general metabolic disturbance associated with renal insufficiency rather than from a high BUN alone [5]. Fukunishi et al. [19] suggested that two factors, advanced age and long-term hemodialysis, were closely related to the delirium development in patients on hemodialysis therapy. The presence of end-stage renal disease on hemodialysis was investigated as an independent significant predictor among several comorbidities in our study. However, the electrolyte imbalance did not contribute to delirium occurrence. Serum creatinine levels were similar in both groups $(2.6 \pm 2.7 \mathrm{mg} / \mathrm{dl}$ vs. $2.2 \pm 2.6 \mathrm{mg} / \mathrm{dl}, \mathrm{P}=0.468$, respectively). The BUN level was higher in the delirium group $(31.3 \pm 18.2 \mathrm{mg} / \mathrm{dl}$ vs. $25.0 \pm 15.4 \mathrm{mg} / \mathrm{dl})$ but with a low statistical significance $(P=0.064)$. Cognitive impairment in dialysis is thought to be associated with cerebrovascular disease and increased mortality [20].

Alcohol consumption is known as an independent risk factor for delirium in some surgeries [21]. In that report, authors determined alcohol abuse if patients consumed more than one drink or bottle of beer on a daily basis in colorectal surgery for carcinoma. In the subjects with critical limb ischemia undergoing surgery, daily intake of alcohol was a potential risk factor in the univariate analyses, but the multivariate analysis did not confirm it as an independent predicting factor [8]. It should be noted that we defined alcohol consumption extensively, compared to previous studies. However, defining alcohol consumption and abuse, as well as quantifying the amount of consumed alcohol is not as easy as commonly thought. Alcohol consumption might have been estimated inaccurately which is one of our study's weak points.

The definitive pathophysiological process of delirium remains uncertain but inflammation has been proposed as one of the possible mechanisms. There exists evidence about the relationship of CRP with neuroinflammatory processes. CRP is associated with the activation of vascular endothelial cells, a process that may explain the susceptibility of patients with organic brain disease to delirium caused by systemic inflammatory conditions [22]. Although there are conflicting research findings about CRP in delirium, one study revealed that CRP levels at or soon after admission appear to be highly predictive of delirium and recovery in acute medical inpatients [23]. Another investigation even demonstrated that with an increase in the postoperative CRP level to $100 \mathrm{mg} / \mathrm{L}$, the risk of delirium after surgery increased by almost 90\% [10]. In the present study, preoperative CRP was identified as a potential risk factor for delirium in univariate analysis, but we did not find the relationship between the elevated CRP levels and the occurrence of delirium in our multivariate evaluation.

The CAM has been widely used as a standardized tool for the identification of delirium and was developed for non-psychiatrically trained personnel [24], but its sensitivity was as low as $50 \%$ when used by individuals with minimal training [25]. In this study, registered nurses in clinical wards administered the CAM to the patients but individual variation with regard to the degree of training could still exist. A delirium diagnosis needs to be confirmed by skilled physicians, using elaborate criteria such as in the DSM (Diagnostic and Statistical Manual of Mental Disorders) or the ICD-10 (International Statistical Classification of Diseases and Health-related Problems, 10th revision). The possibility of inaccurate diagnosis is one of the limitations in our study.

In conclusion, this study investigated the incidence and risk factors of postoperative delirium following major leg amputation. We found that approximately $40 \%$ of the elderly patients suffered from delirium after major leg amputation. Among the perioperative variables, mortality during six months, alcohol, and hemodialysis were significantly related to the development of delirium. Patients with an elevated CRP level in the preoperative evaluation, ICU stays, longer duration of ICU stays, and postoperative complications, tended towards delirium development in the postoperative period. An accurate diagnosis, early intervention, and appropriate management of elderly patients with risk factors for postoperative delirium in leg amputation surgery need to be taken into consideration by physicians.

\section{ORCID}

Young-Hee Shin, https://orcid.org/0000-0001-6609-4378 Jin Sun Yoon, https://orcid.org/0000-0002-7133-1814

Hee Jung Jeon, https://orcid.org/0000-0003-2439-2654

Youngbae B Kim, https://orcid.org/0000-0003-3966-0949

Young Soo Kim, https://orcid.org/0000-0003-3153-9722

Ju Young Park, https://orcid.org/0000-0002-2301-8057

\section{References}

1. Dyer CB, Ashton CM, Teasdale TA. Postoperative delirium. A review of 80 primary data-collection studies. Arch Intern Med 1995; 155: 461-5. 
2. Sieber FE. Postoperative delirium in the elderly surgical patient. Anesthesiol Clin 2009; 27: 451-64.

3. Sasajima Y, Sasajima T, Uchida H, Kawai S, Haga M, Akasaka N, et al. Postoperative delirium in patients with chronic lower limb ischaemia: what are the specific markers? Eur J Vasc Endovasc Surg 2000; 20: 132-7.

4. van der Mast RC. Postoperative delirium. Dement Geriatr Cogn Disord 1999; 10: 401-5.

5. Sasajima Y, Sasajima T, Azuma N, Akazawa K, Saito Y, Inaba M, et al. Factors related to postoperative delirium in patients with lower limb ischaemia: a prospective cohort study. Eur J Vasc Endovasc Surg 2012; 44: 411-5.

6. Guenther U, Riedel L, Radtke FM. Patients prone for postoperative delirium: preoperative assessment, perioperative prophylaxis, postoperative treatment. Curr Opin Anaesthesiol 2016; 29: 384-90.

7. Elsayed S, Clavijo LC. Critical limb ischemia. Cardiol Clin 2015; 33: 37-47.

8. van Eijsden WA, Raats JW1, Mulder PG2, van der Laan L. New aspects of delirium in elderly patients with critical limb ischemia. Clin Interv Aging 2015; 10: 1537-46.

9. Visser L, Prent A, van der Laan MJ, van Leeuwen BL, Izaks GJ, Zeebregts CJ, et al. Predicting postoperative delirium after vascular surgical procedures. J Vasc Surg 2015; 62: 183-9.

10. Pol RA, van Leeuwen BL, Izaks GJ, Reijnen MM, Visser L, Tielliu IF, et al. C-reactive protein predicts postoperative delirium following vascular surgery. Ann Vasc Surg 2014; 28: 1923-30.

11. Inouye SK1, van Dyck CH, Alessi CA, Balkin S, Siegal AP, Horwitz RI. Clarifying confusion: the confusion assessment method. A new method for detection of delirium. Ann Intern Med 1990; 113: 941-8.

12. Oken MM, Creech RH, Tormey DC, Horton J, Davis TE, McFadden ET, et al. Toxicity and response criteria of the Eastern Cooperative Oncology Group. Am J Clin Oncol 1982; 5: 649-55.

13. Raats JW, van Hoof-de Lepper CC, Feitsma MT, Meij JJ, Ho GH, Mulder PG, et al. Current factors of fragility and delirium in vascular surgery. Ann Vasc Surg 2015; 29: 968-76.

14. Beckman JA, Creager MA. Critical limb ischemia and intermediate-term survival. JACC Cardiovasc Interv 2014; 7: 1450-2.

15. Kalish VB, Gillham JE, Unwin BK. Delirium in older persons: evaluation and management. Am Fam Physician 2014; 90: 150-8.

16. Vinkers DJ, Stek ML, van der Mast RC, de Craen AJ, Le Cessie S, Jolles J, et al. Generalized atherosclerosis, cognitive decline, and depressive symptoms in old age. Neurology 2005; 65: 107-12.

17. Robinson TN, Raeburn CD, Tran ZV, Angles EM, Brenner LA, Moss M. Postoperative delirium in the elderly: risk factors and outcomes. Ann Surg 2009; 249: 173-8.

18. Fried LP, Ferrucci L, Darer J, Williamson JD, Anderson G. Untangling the concepts of disability, frailty, and comorbidity: implications for improved targeting and care. J Gerontol A Biol Sci Med Sci 2004; 59: 255-63.

19. Fukunishi I, Kitaoka T, Shirai T, Kino K, Kanematsu E, Sato Y. Delirium in patients on hemodialysis therapy. Nephron 2002; $90: 236$.

20. Iyasere O, Brown EA. Cognitive function before and after dialysis initiation in adults with chronic kidney disease-a new perspective on an old problem? Kidney Int 2017; 91: 784-6.

21. Patti R, Saitta M, Cusumano G, Termine G, Di Vita G. Risk factors for postoperative delirium after colorectal surgery for carcinoma. Eur J Oncol Nurs 2011; 15: 519-23.

22. Uchikado H, Akiyama H, Kondo H, Ikeda K, Tsuchiya K, Kato M, et al. Activation of vascular endothelial cells and perivascular cells by systemic inflammation-an immunohistochemical study of postmortem human brain tissues. Acta Neuropathol 2004; $107: 341-51$.

23. Macdonald A, Adamis D, Treloar A, Martin F. C-reactive protein levels predict the incidence of delirium and recovery from it. Age Ageing 2007; 36: 222-5.

24. Rade MC, Yadeau JT, Ford C, Reid MC. Postoperative delirium in elderly patients after elective hip or knee arthroplasty performed under regional anesthesia. HSS J 2011; 7: 151-6.

25. Sands MB, Dantoc BP, Hartshorn A, Ryan CJ, Lujic S. Single Question in Delirium (SQiD): testing its efficacy against psychiatrist interview, the Confusion Assessment Method and the Memorial Delirium Assessment Scale. Palliat Med 2010; 24: 561-5. 